\title{
Beautification of Chinese Architectural Images in the New Media Age
}

\author{
Shan Huang ${ }^{*}$, Tingyu Liư ${ }^{2}$, Jinni Bai ${ }^{1}$ \\ ${ }^{1}$ School of Architecture, Zhengzhou University, Zhengzhou 450001, Henan Province, China \\ ${ }^{2}$ School of Landscape Architecture, Beijing Forestry University, Beijing, China \\ *Corresponding author: Shan Huang, jiangshanxingji@163.com
}

Copyright: (C) 2022 Author(s). This is an open-access article distributed under the terms of the Creative Commons Attribution License (CC BY 4.0), permitting distribution and reproduction in any medium, provided the original work is cited.

\begin{abstract}
From the perspective of communication science, the communication of architectural images in the new media age has an obvious beautifying trend. Due to the differences in politics, economics, and cultural environment between China and western countries, the beautification of architectural images in China is a unique phenomenon. This study classifies the beautification of Chinese architectural images into different types in terms of image communication: audience orientation, time orientation, space orientation, and cultural orientation. By investigating and analyzing relevant cases, this study explores the beautification of Chinese architectural images in the new media age and puts forward thoughts and evaluation, aiming to better comprehend the relationship between beautification and architectural communication.
\end{abstract}

Keywords: Beautification; Chinese architectural image; New media age; Image communication

Online publication: January 12, 2022

\section{Introduction}

In the context of new media age, the communication of architecture can be understood as the last step to be considered in the design process. The content, media, and effect of communication influence the entire architectural environment directly or indirectly, leading to a series of hot topics represented by online wellknown architectures, which reflect a unique phenomenon with characteristics of the times in the communication process of architecture. A representative trend among these is the beautification of architectural images. Due to its remarkable effect on communication, the discussion on its social, cultural, and practical significance is still worthwhile despite this trend being lesser known. Therefore, proceeding with the comparison of ideology and cultural environment between China and the west, this paper discusses the phenomenon from different communication orientations and attempts to provide different perspectives of the design and communication processes of architecture by exploring the beautification of architectural images.

\section{Beautification of images}

\subsection{Definition}

In Wandering in the Beauty, Zong Baihua said, "Beauty mediates contradictions and draws in harmony." In Chinese, beautification is translated as "mei yan hua," in which "mei" means beautifying, "yan" refers to appearance, and "hua" equates to the suffix "-tion," which is defined as the action or a state of being. Therefore, the phrase "mei yan hua" (beautification) has a deep implication of "the alteration of appearance 
to achieve harmony in the form." There are various media subjects of beauty, among which image, one of the most widely communicated media, has expected research value. In the semiotic sense, an image is a systematic form of rules and symbols. It is a symbol indicating the object under some common characteristics between itself and the object expressed by it. The purpose of beautification is to create an ideal image by improving the harmony of the image itself through editing, which can be understood as a self-display and management strategy of impression ${ }^{[1]}$.

\subsection{Analysis of the beautification of non-architectural images}

With the development of image editing, the change of media, and the increasing pursuit of beauty among people, beautification of images is increasingly common ${ }^{[2]}$. Especially the ones on social media, such as MeituPic, a Chinese beauty camera application, which has attracted wide attention in recent years. In a survey, the consensus of the respondents points to the development trend of today's society whereby their attention is on pursuing beauty. In this era of "appearance anxiety," opportunities tend to favor those with a better appearance. Hence, people receive attention and praise from others by posting beauty-filtered photos on social platforms to meet their social needs. In Owen Goffman's impression management theory, people's daily social communication is comparable to a stage performance ${ }^{[3]}$. Everyone is trying their best to keep their image consistent with the current social situation to ensure that other people respond to them. This phenomenon reflects the noticeable beautifying trend in the new media age.

\subsection{Analysis of the beautification of architectural images}

Architecture and architectural images exist intertextually ${ }^{[4]}$. Architectural images have unique characteristics compared with those of other areas. For example, in architectural photography, tilt-shift lens and high-definition cameras are usually used to capture the light influence on certain architectures. Furthermore, some architectural photographers have attempted to communicate tactile and auditory information through visual languages, such as through light, color, and composition. Accordingly, it is worthwhile to learn this separately. However, unlike documentary photography, the beautification of architectural images has artistic or other purposes. Therefore, the academic world in the new media age generally calls it "conceptual photography." Architectural images are part of a form of media art.

Although globalization has brought about strong homogenization in modern media, the fundamental differences between China and the west in ideology and cultural environment still contribute to their distinctions in the beautification of architectural images. Therefore, combing the differences is beneficial to understand the beautification of Chinese architectural images. At the same time, exploring the beautification of architectural images with Chinese characteristics may play a positive role in the regression of the sense of place and belonging.

\section{Differences between China and the west}

\subsection{Differences between Chinese and western built environments}

Just as Cheng Taining, an academician, argued that civilizations seek common ground and cultures raise differences ${ }^{[5]}$, the differences in cultural landscapes lead to the differences between Chinese and Western architectural environments.

First, from the perspective of history, western architecture focused on the physical form and spatial expressions, whose prototype was a complex space overlaid by multiple structural units. The construction of traditional western architecture appeared as three-dimensional vertical expansion, showed the spatial 
pattern of concentration, and attached great importance to the rational beauty of form, which includes the structure, shape, decoration, and volume of the building, having a strong sense of sculpture and tension. However, traditional Chinese architecture focused on the artistic prospect of space. Its prototype and unit were represented by "jian" (a surface surrounded by four columns). By repeatedly juxtaposing them, the architecture presents a two-dimensional horizontal linear and longitudinal advancement. It emphasizes practice and spatial sequence as well as stresses the effect of axial symmetry and depth ${ }^{[6]}$.

From the perspective of modern architecture, as Arata Isozaki had mentioned, after the 1950s, various architectural forms in the world have been consumed by China. The development of local Chinese architecture has seen a strong influence through internationalization. It is on a tough road, on which traditional Chinese architectural forms attempt to be modern, while western architectural forms are being nationalized ${ }^{[7]}$.

\subsection{Differences between Chinese and Western architectural images}

As a medium to spread ideas, architectural images reflect the differences between Chinese and Western architecture and architectural media accordingly. Due to the well-developed political and economic situations, architectural images in western countries can meet the needs of consumers and participate in the process of consumption ${ }^{[8]}$. As opposed in China, where political and economic development is insufficient, this orientation is still in its infancy. The Chinese ideology and construction environment have shaped a unique urban and architectural culture ${ }^{[9]}$. In the new media age, the openness and sharing of a wide range of public audiences are promoted. Therefore, architectural images tend to reflect the characteristics of the society. Architectural images shoulder the role of cultural inheritance, especially those cities and architectures that reflect the historical features and living habits of the Chinese. Moreover, with the trend of internationalization, Chinese architectural images are still influenced by western ones, making them a mixture of both sides.

With the arrival of the new media age and the formation of the "architecture-architect-architectural image(beautified)-market" system, the differences between Chinese and western beautification of architectural images come from the differences between architecture and architectural images. To sum up, the beautification of Chinese architectural images reflects the mixed characteristics of Chinese architectural forms, the initial elements of catering to consumer needs, as well as the attributes of inheriting Chinese urban and architectural culture, which integrates Chinese aspects on the basis of the west.

\section{Beautification of Chinese architectural images}

In the new media age, as the mainstream communication medium, the internet promotes architectural communication. As a result, many architectural media have moved from traditional to online ones.

Compared with traditional media, the public hopes to seek a more powerful expression, so visualized expression has become the new trend in architectural communication. The beautification of Chinese architectural images is classified and expounded according to different communication directions: audience orientation, time orientation, space orientation, and culture orientation.

\subsection{Audience orientation}

On May 10, 2015, "Yitiao" uploaded a video on its WeChat official account with the headline of "The Loneliest Library in China." It was popular on the internet and received 600 million views across the network (Figure 1). The video showed a library facing the sea and standing alone on an empty beach as if it was the end of time. As a result, many tourists visited the library, with the highest daily flow of more than 3,000 people, far more than the library can contain. Sharon Zukin, an American professor of sociology, 
argued that urban changes should take politics, economics, society, and culture into account along with capital, property, media preferences, and consumer preferences.

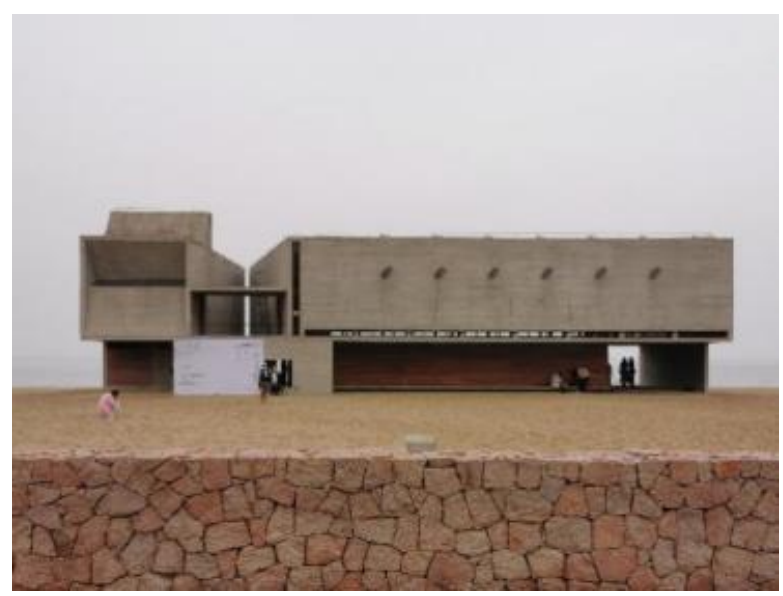

Figure 1. Library facing the sea (from a website)

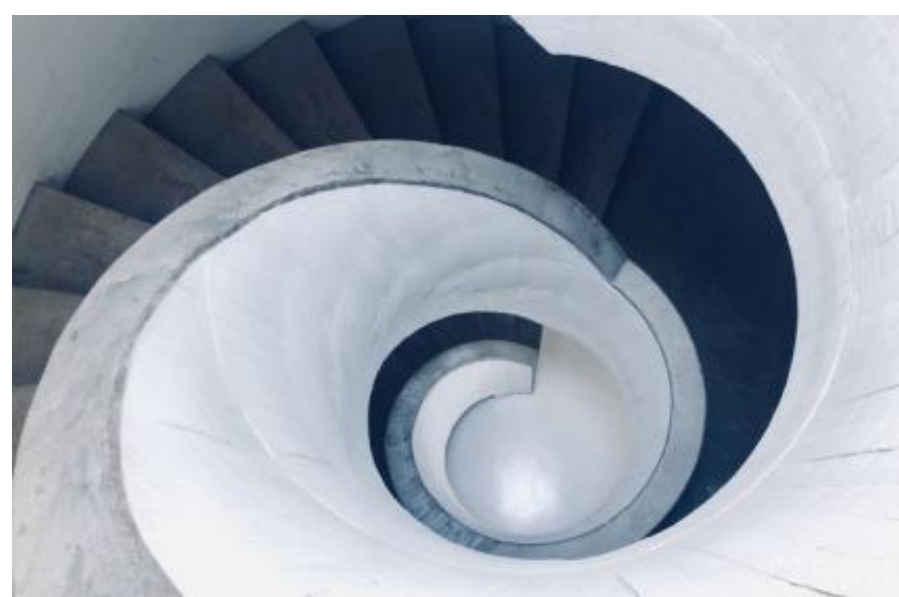

Figure 2. Inside the Dune Art Museum (from Mafengwol, a website)

The library in China represents a successful case of image communication in the new media age. Based on communication data, design information, and field investigation, an elaboration on the audience orientation will be discussed in consideration of this seaside library. In this case, four types of audiences are included in image communication: investors, developers, consumers, and architects.

As far as investors are concerned, this project has become famous throughout the internet due to the widespread architectural photography images. These images have attracted many tourists and brought substantial sales records to Anaya Real Estate, its developer, who managed to realize the online-to-offline (O2O) mode of cultural real estate. Since then, the developer has continuously cooperated with domestic star architectural firms to create distinctive complementary buildings, including Anaya Auditorium, Dune Art Museum (Figure 2), Anaya Art Center, etc. ${ }^{[10]}$. For consumers, attracted by the lonely, genuine, meditative, and mysterious atmosphere of the sea conveyed by the images, urban youth visit the library to pursue the psychological demand of "a slow life." At the same time, Anaya's tourism real estate development provides cultural, leisure, and living facilities, which meet the cultural demands of the urban middle class and personalize its spatial image in the process of social media communication. Visitors consider these images as a label of a "beautiful life," while architects drive architectural designs into the professional field. Differing from the emphasis on the lonely atmosphere on social media, architects make serious, orthodox, and academic discussions about this seaside library. They ponder about the relationship between two-dimensional architectural images and architectural designs from the architectural perspective of site, space, structure, section, material, etc.

\subsection{Time orientation}

In the era of picture-reading nowadays, architectural photography shapes people's understanding of architecture. When people do not have the opportunity to experience on-site architecture, images become the best medium to reflect the relationship among architectural space, light and shadow, scale, color, as well as texture. Moreover, the beautification of architectural images is widely found in exhibitions, announcements of new works, travel guides, and printed publications. Therefore, architectural photography has increasingly become an active embellishing method for architectural communication.

The beautification of architectural photography includes two stages: shooting and effect. The shooting stage focuses on the equipment, light, composition, color, and other aspects. For example, photographers primarily use large and medium format cameras, consider the relationship between height, angle, distance, 
and the characteristics of the architecture, as well as take into account of the use of light, color control, and indoor light. The post-processing in photography is equally important, such as Photoshop, Lightroom, and other software to adjust the highlight and shadows or exposure value, saturation, clarity, perspective, and other elements ${ }^{[11]}$. For the later stage, architectural photography is not only the visual expression of the architectural form and environment, facade, interior space, as well as internal and external decoration, but also the process of recreating, integrating the views and emotions of the photographer, as well as displaying the cognitive concept of the photographer to the world. Taking the urban photography in Chongqing with cyberpunk style as an example, the time-oriented beautification of architectural photography is elaborated.

With the rapid development of Chongqing, modern skyscrapers, colorful neon lights, and magical urban structures with a strong sense of space create a city that is full of futuristic cyberpunk style, becoming the preferred location of photographers (Figure 3 and Figure 4). A series of photographs of Chongqing have won much attention on the internet, making Chongqing an online celebrity city. Photographers tend to focus on Chongqing's urban rail transit, such as viaducts, tunnels, cableways, bridges, and skyscrapers. They usually use sizeable wide-angle lens to shoot in a low angle or shoot perspective in an elevation angle or use a wide-angle lens in an elevation angle. Splicing, symmetry, contrast, reconstruction, and other techniques strengthen the visual impression of conflict aesthetics in the scene composition ${ }^{[12]}$. In postprocessing, in terms of hue, the colors are adjusted uniformly, focusing on improving the blue and purple saturation as well as the overall picture brightness and lighting brightness. Geometric neon light effects of different shapes are drawn to enhance the sense of science and technology. The technological and futuristic elements of urban space are reflected with a sense of fiasco, such as dislocation stretching and dynamic blurring ${ }^{[13]}$, thus subverting the audience's cognition of architectural images in the objective real-life world and presenting the concept of urban dystopia.

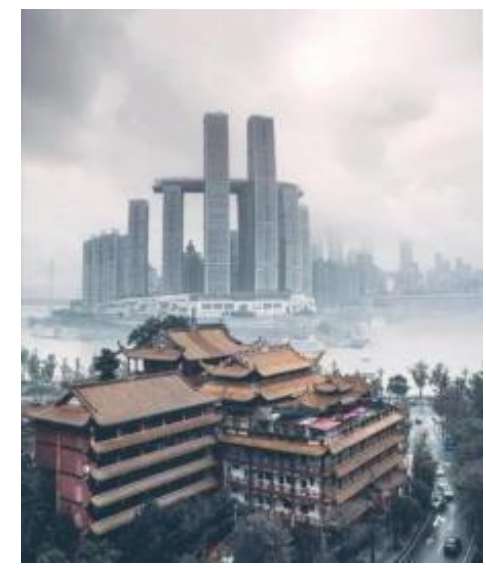

Figure 3. Raffles City Chongqing (a shot by AKA_SK8Simon)

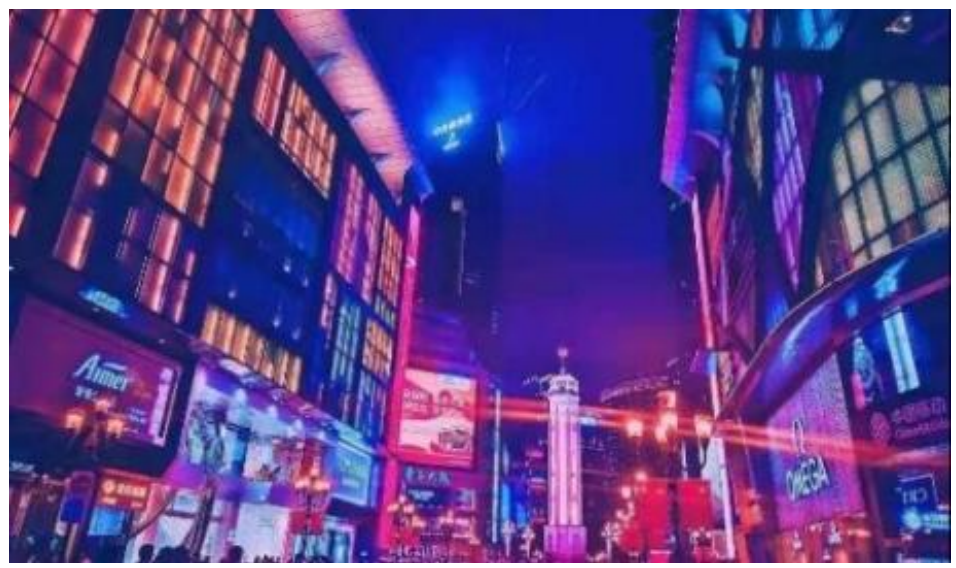

Figure 4. Nearby Chongqing Liberation Monument

(a shot by Marcelo)

\subsection{Spatial orientation}

Those who perceive architectural images are also users of architecture to a certain extent. In that case, architectural design is influenced by images, which illustrate and reconstruct architectural design. For example, in an actual project, the interior of the minaret and the spiral staircase of the Yangtze River Art Museum convey the commemorative atmosphere of the "anchor point" of the architecture through photography filled with a sense of light, creating a sense of place. In the design of Nestle's Sense Cafe in Beijing, the red ribbon is a "soft intervention" in the courtyard. The photos enhance the color of the ribbon, breaking through a series of boundary relations of the old city. Other than that, the glass facade of Depot Boijmans Van Beuningen is made of reflective mirrored panels, which emphasize the visual effect of the 
art warehouse and its surroundings. Taking Mulan Prairie House as an example, this paper further looks into the beautification of architectural images with spatial orientation.

Mulan Prairie House was one of the most reported architectures in 2017. The articles attached with the architectural photographs of this architecture have been read 100 million times on the internet, making it an excellent sample for studying the beautification of architectural photography images (Figure 5). The simplified form of the architecture, the unique environment with mountains and grasslands as the background, as well as the graphic materials create a photogenic scene to stimulate images visually. Mulan Prairie House is located in the northeast of Hebei Province, connected with the Inner Mongolia grassland. The effect image is detached, enjoying the grassland with blue sky and white clouds with its unique location. The architecture prioritizes the form, imitating the Mongolian yurt, whose image expression is simple and easy to perceive. Zhang Haiao, an architect, introduced mirrors, glass, aluminum, and other materials unrelated to the main structure but have a strong sense in pictures to enhance the visual effect of the interior and exterior space. For example, outside the architecture, the quaint tea room is wrapped in mirrored metal panels, and a rectangular volume that extends from the yurt is wrapped in rubble veneers.
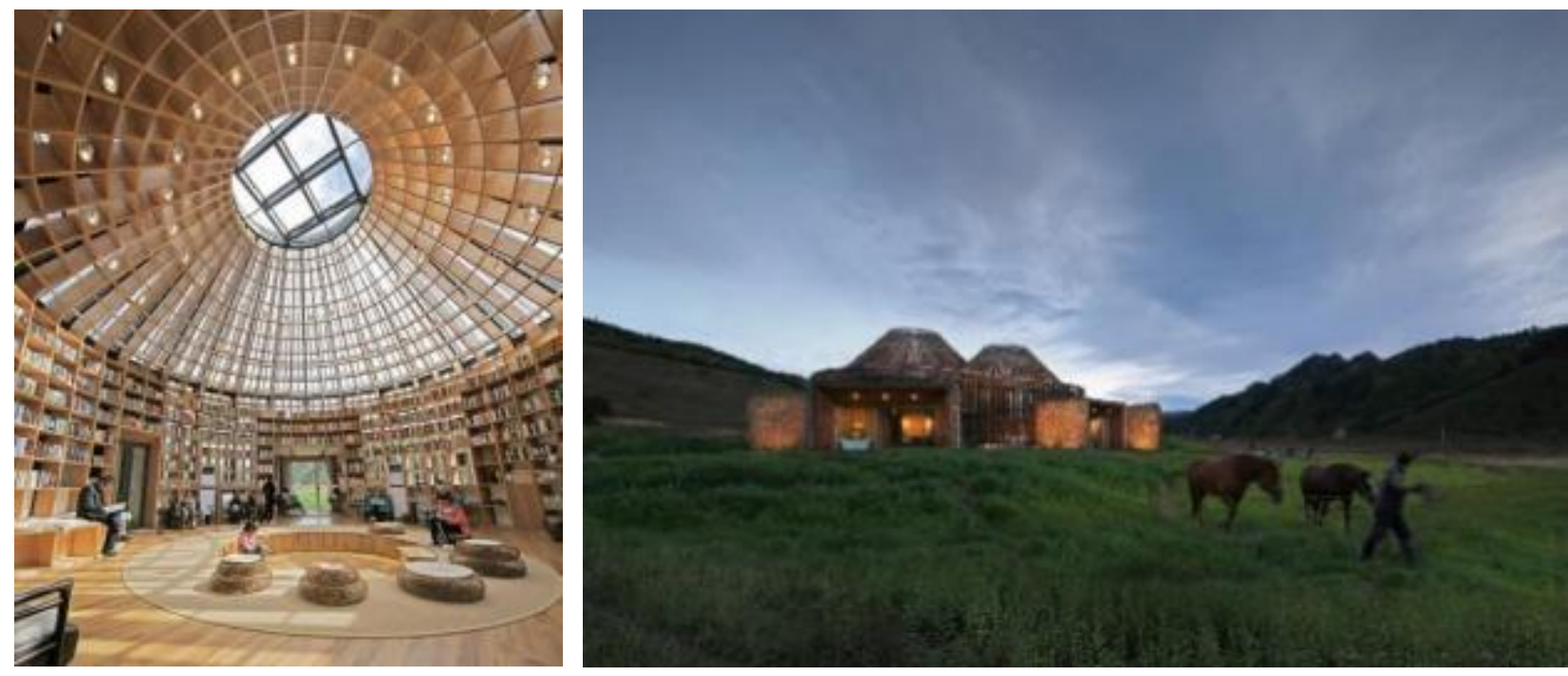

Figure 5. Mulan Prairie House (shots by Su Shengliang, from https://www.gooood.cn)

The process from drawing to architecture and then from the architecture to the image completes the "design - construction - use" routine or the so-called "production and consumption" of the architecture loop ${ }^{[14]}$. When images are the mainstream of presentation, image consumption and architectural design are equally important in this process. Therefore, in a space where the beauty of images is prioritized, the viewer may not be bothered even if the space is uncomfortable, non-durable, non-functional, or impractical. Image hides a series of information of the architecture, such as the location, material, function, etc. Visual effect has become the critical consideration in design.

\subsection{Cultural orientation}

Architectures and cities grow from status symbols to stories, images, and network traffic. Architectural design is for the minority, but it is open to the public. Traditional two-dimensional architectural drawings limit architecture to professionals, but beautified architectural images in picture books and photographic images circulate architecture's cultural, historical, social, regional, and national characteristics in a way that is more acceptable to the public. Drawing Changsha Taiping Street is taken as an example to explore the positive effects of architectural paintings on architecture, city, and culture. 
Drawing Changsha Taiping Street adopts the form of an architectural picture book and takes historical events as well as current narration as spatial clues. Moreover, with the urban renewal of Chaozong Street, the most representative historical and cultural blocks in Changsha have been captured, highly reflecting the food and entertainment culture ${ }^{[15]}$ (Figure 6). The team profoundly excavates the gene of the city itself, uses its social, historical, and cultural resources, as well as visualizes the vivid scenes of streets and corners of Changsha to help the public understand the participation of the architectural space in urban development.
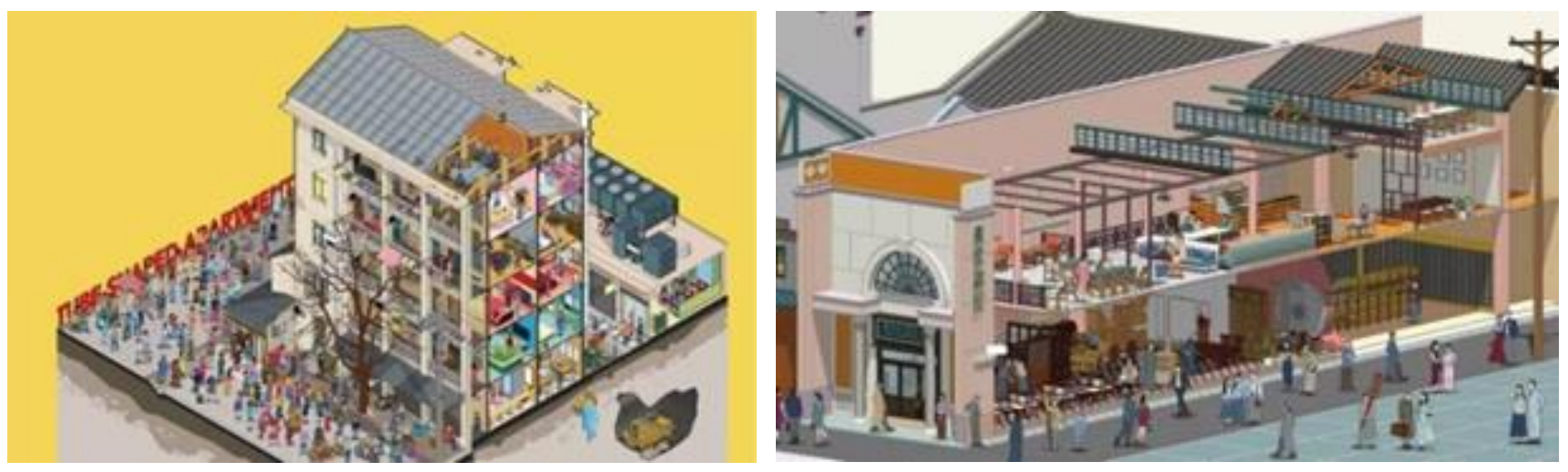

Figure 6. Drawing Changsha Taiping Street

As a new cultural communication medium, Drawing Changsha Taiping Street is a reproduction of Changsha's history, existing space, and market culture as well as a reminder of history and urban space to awaken citizens' cultural identity in urban historical blocks. Drawing Changsha Taiping Street promotes the protection and development of culture by cultural communication rather than the previous economyoriented model, which is also a new strategy to explore the revival of urban historical blocks in the new media age. Architecture picture books are stories with historical value, artistic value, technical value, and social thinking. They integrate architectural and environmental information as well as the image content of urban culture and record them into books through painting to attract the public to "taste" the cities and architectures beyond the inherent standards.

\section{Conclusion}

In conclusion, the impetus for the beautification of Chinese architectural images comes from various sources, with multiple influencing factors from different directions. On the whole, in the age of new media, the communication of Chinese architectural images plays a critical role in the judgment of architectural design, architectural influence, architects themselves, and also the entire architectural environment. Although the beautification of images has brought more attention to the communication of architecture, the impact of values and judgment guidance behind the communication still requires further discussion.

\section{Disclosure statement}

The authors declare that there is no conflict of interest.

\section{References}

[1] Ran H, Liu Y, 2021, Motivation, Meaning and Interpretation of Beauty: A Qualitative Analysis of Photo Editing Behavior of Young Women. News and Writing, 2021(04): 32-39.

[2] Zhu Y, Sun A, Ye Y, et al., 2021, Analyze the Social Behavior of College Students Using Beauty Filters in Selfies - Based on Impression Management Theory. Media Forum, 4(02): 156-158. 
[3] Goffman O, 1989, Self-Presentation in Daily Life [Huang A, Feng G, Trans.], Zhejiang People's Publishing House, Zhejiang, 06.

[4] Yang X, 2015, The Intertextuality of Architecture and Image a Cross-disciplinary Study Based on Phenomenological Pondering. Xi'an University of Architecture and Technology.

[5] Jin L, 2015, A "Benchmark" Work That Fills the Confidence of Chinese Contemporary Architectural Culture - Impressions After Reading "Interview with Academician of Architecture". Architectural Design Management, 32(03): 36-39.

[6] Qi W, Wang X, 2021, Comparison of Chinese and Western Traditional Architecture Space Schema and Construction in Cross-Cultural Context. Social Science Front, 2021(06): 248-253.

[7] Sun J, 2014, Looking at the Consideration Standards of Chinese Contemporary Architecture from the "Top Ten Chinese Contemporary Architecture". Art Observation, 2014(09): 22-23.

[8] Zhang L, 2014, Five orientations of Today's Architectural Media. Times Architecture, 2014(06): 5859.

[9] Ou X, Wu G, 2017, "Independence and Sociality" - A Probe into the Development Trend of Chinese Contemporary Architectural Media in the Internet Era. Residential District, 2017(05): 46-50.

[10] Wang X, 2021, The Image Construction and Spatial Identity of Internet Celebrity Architecture - Take Anaya's Image Dissemination as an Example. Grand View of Fine Arts, 2021(08): 132-134.

[11] Xu M, Sun X, Liu L, 2020, Architectural Photography-Illustrating and Reconstructing the Architectural World. Art Grand View, 2020(33) 86-87.

[12] Zhao X, 2015, Research on Architectural Photography Techniques in the Sense of Architecture. Dalian University of Technology, Dalian.

[13] Lu X, 2021, Research and Application of Harbin Cyberpunk Architecture Photography. Harbin Normal University, Harbin.

[14] Yu Y, 2018, The Dual Identity of Architecture and Communication - Mulan Grassland Home. Times Architecture, 2018(04): 110-118.

[15] Wang $\mathrm{W}, \mathrm{Ou} \mathrm{X}, \mathrm{Xu} \mathrm{H}$, The Image Narration and Reproduction of Historical Districts - The Creation and Thinking of "Painting Changsha Taiping Street". Decoration, 2018(07): 118-120.

Publisher's note

Bio-Byword Scientific Publishing remains neutral with regard to jurisdictional claims in published maps and institutional affiliations. 